\title{
Azeotropy Breaking in Refrigerant Blends with Ionic Liquids
}

\author{
V. Mazur ${ }^{*}$, S. Haddad and D. Nikitin \\ National Academy of Food Technologies, Odessa, Ukraine \\ Abstract: The principal aim of this work is to study azeotropy breaking in the refrigerant blends with ionic liquids (IL). \\ The global phase diagram approach is applied to correlate azeotropic data for binary mixtures based only on critical \\ properties and acentric factor of the individual components in mixtures. Analytical expressions to predict azeotropy \\ phenomena in terms of critical parameters of pure components and binary interaction parameters are given. The \\ eventual azeotropy appearance in the refrigerant - IL blends is discussed and conclusion about highly improbable \\ azeotropic blend formation for these systems is given. Global phase behavior of ionic liquid - industrial refrigerant blends \\ is analyzed and possible III, IV and/or V types according to the classification scheme of Scott and van Konynenburg [1] \\ are established. The azeotropy breaking in binary refrigerant mixtures with ionic liquid adding is predicted.
}

Keywords: Phase equilibria, azeotropy breaking, ionic liquids, refrigerant blends.

\section{INTRODUCTION}

lonic liquids (IL) are one of prospective new working media for different environmentally friendly technologies. Practically undetectable vapour pressure is considered the ILs as ideal solvents replacing conventional solvents in the frame of a "green chemistry'. The ILs detect a selective solubility for particular components in fluid mixtures and can serve as extraction media in separation of ozone depleting refrigerant blends. Combination of ionic liquids with conventional natural and synthetic refrigerants promotes the efficiency increasing of absorption processes due to non-volatile ionic liquids (absorbents).

ILs are tunable working fluids as far as a variation of different «R - » groups and sufficient selection of cation/anion ratio allow to meet a desired trade off solution among density, viscosity, melting point, and other physicochemical properties. The number of cation/anion combinations can reach astronomic values. There are many studies published by Aki et al. [2], Ren et al. [3], Shiflett and Yokozeki [4-12], Shiflett et al. [13-15], Yokozeki and Shiflet [16], Raeissi et al. [17] and others where phase equilibria measurements for refrigerants R23, R125, R41, R134a, R143a, R152a, R161, R744 и R717 with different ionic liquids were carried out.

The principal aim of this work is to study azeotropy breaking in the refrigerant blends with ionic liquids (IL). The work is organized as follows. In the first section, we review the global phase behavior of binary mixtures

*Address correspondence to this author at the National Academy of Food Technologies, Odessa, Ukraine; Tel: +38 048 7209168;

Fax: +38 048 7248672; E-mail: mazur@paco.net and give an analytical expression for azeotropy selection criterion for the Soave - Redlich - Kwong (SRK) model [18], [19]. In the second section, we simulate phase behavior of R134a and R1234yf with IL. Azeotropy breaking in the R134a - R1234yf blend at IL doping is considered as illustration of zeotropy behaviour in the refrigerant - ILS mixtures. The possibility to detect azeotropic states in R744 - IL blends is discussed and pessimistic prognosis to find a sufficient IL is given.

\section{GLOBAL PHASE BEHAVIOUR OF REFRIGERANT - IONIC LIQUID BLENDS}

Mixtures of natural and synthetic refrigerants with ILs generate a broad range of phase behavior in refrigerant mixtures at low temperatures. A theoretical analysis of the topology of phase diagrams is a very useful tool for understanding the phenomena of phase equilibrium that are observed in multicomponent refrigerant blends. The pioneering work of van Konynenburg and Scott [1] demonstrated that the van der Waals one fluid model has wide possibilities of qualitative reproducing the main types of phase diagrams of binary fluids. The proposed classification was successful, and is now used as a basis for describing the different types of phase behavior in binary mixtures. A more rigorous classification of the typical characteristics of equilibrium surfaces and phase diagrams of binary mixtures is given in the work of Varchenko [20], in which it is proved that the number of topologically different rearrangements equal to eight. At present, the topological analysis of equilibrium surfaces of binary fluid systems contains 26 singularities and 56 scenarios of evolution of the $p-T$ diagrams [21].

Conventional phase diagrams are a visual representation of the state of a substance as a function 
of temperature $T$, pressure $p$, and component concentration $x$. Therefore, they are used as a tool for visual analysis of the physical picture of the solubility phenomena. These variables are inherently different. Pressure and temperature are the "field" variables that are the same for all phases coexisting in equilibrium. The molar fraction is the "density" that is in principle different for different phases. Global phase diagrams of binary mixtures represent boundaries between different types of phase behavior in a dimensionless space of equation of state parameters. For the first time, the idea of mapping the surface of phase equilibria onto the space of field variables, i.e., parameters of an equation of state, was proposed by van der Waals. The boundaries of the global phase diagrams (tricritical points (TCPs), double critical end points (DCEPs), azeotropic line, etc.) divide the space of model parameters into the regions that correspond to the different types of phase behavior. The mapping of the global surface of a thermodynamic equilibrium onto the space of parameters of an equation of state is the most extensive and sequential system of criteria for predicting the phase behavior of a binary mixture. The types of phase behavior within the Van Konynenburg and Scott classification scheme of interest are characterized as follows.

- $\quad$ Type I: a single permanent critical line between $\mathbf{C}_{\mathbf{I}}$ and $\mathbf{C}_{2}$;

- Type II: one critical line connecting $\mathbf{C}_{\mathbf{I}}$ and $\mathbf{C}_{2}$, another line going from $\mathbf{C}_{\mathrm{m}}$ to a critical endpoint;

- Type III: one critical line going from $\mathbf{C}_{\mathbf{l}}$ to an upper critical endpoint, another line going from $\mathbf{C}_{2}$ to $\mathbf{C}_{\mathbf{m}}$; Type III-H: a subclass of III having hetero-azeotropic three-phase curve. Type III-A: a subclass of III with a genuine positive azeotropic line.

- $\quad$ Type IV: one critical line going from $\mathbf{C}_{\boldsymbol{|}}$ to an upper critical endpoint, a second critical line going from $\mathbf{C}_{2}$ to a lower critical endpoint, a third line going from $\mathbf{C}_{\boldsymbol{m}}$ to an upper critical endpoint.

- Type V: similar to IV, but without the low temperature critical curve going to $\mathbf{C}_{\mathbf{m}}$.

- Type V-A: a subclass of $V$ with a genuine negative azeotropic line.

- $\quad$ Type VI: involving closed-loop liquid-liquid immiscibility at low temperatures and practically impossible for supercritical conditions.
Here $\mathbf{C}_{1}$ and $\mathbf{C}_{2}$ are critical points of refrigerant and ionic liquid; $\mathbf{C m}$ is hypothetic critical point beyond solidification line. Critical point allocation of main refrigerants [22] and hypothetic critical points some imidazolium based ionic liquids [3] are presented in Figure 1. Global phase diagram can be constructed for given equation of state model.

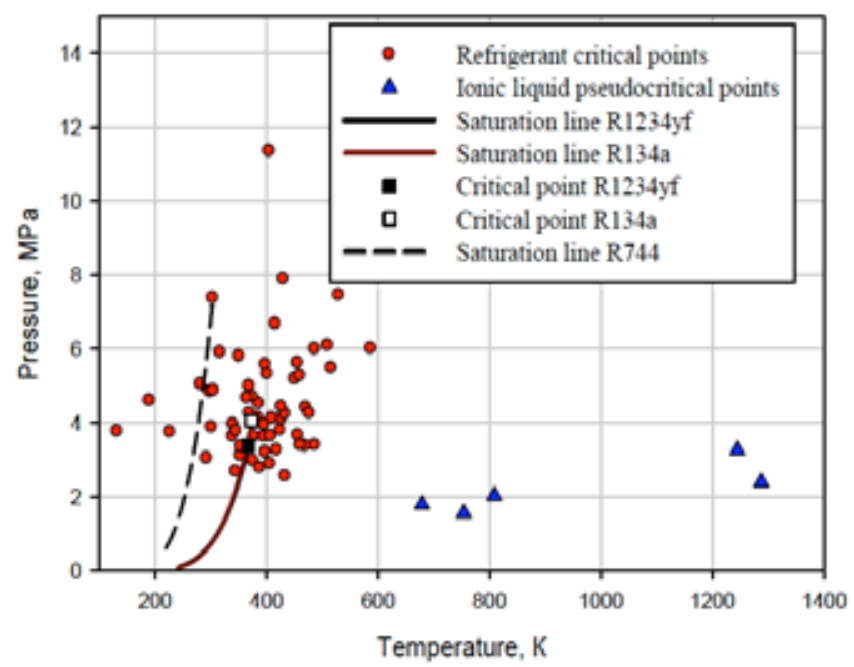

Figure 1: Critical point allocation of main refrigerants and ionic liquids.

To describe thermodynamic and phase behavior the refrigerant - IL blends in this study we use the one fluid model of the SRK equation of state $[18,19]$.

$p=\frac{R T}{v-b}-\frac{a(T)}{v(v+b)}$

where $R$ is the universal gas constant and $v$ is the molar volume; the model parameters $a$ and $b$ depend on the molar composition of $x_{i}$ and $x_{j}$ with respect to the components $i$ and $j$. The respective model parameters $a$ and $b$ are determined by quadratic dependences on composition and classical combining rules for the different pairs of interacting molecules $a_{i j}$ and $b_{i j}$ :

$$
\begin{aligned}
& a=\sum_{i=1}^{N} \sum_{j=1}^{N} x_{i} x_{j} \sqrt{a_{i i} a_{i j}}\left(1-k_{i j}\right), \\
& b=\sum_{i=1}^{N} \sum_{j=1}^{N} x_{i} x_{j} \frac{\left(b_{i i}+b_{i j}\right)}{2}\left(1-l_{i j}\right), \\
& a_{i i}=0.4274 \frac{R^{2} T c^{2}}{P_{c}, i i}, b_{i i}=0.866 \frac{R T_{c, i i}}{P_{c, i i}} \\
& a(T)=0,4274\left(\frac{R^{2} T_{c, i i}^{2}}{P_{c, i i}}\right)\left\{1+m\left[1-\left(\frac{T}{T_{c, i i}}\right)^{0.5}\right]\right\}^{2}
\end{aligned}
$$


$m=0,480+1,57 \omega-0,176 \omega^{2}$.

Global phase diagrams of binary fluids represent the boundaries between different types of phase behaviour in a dimensionless parameter space. The dimensionless coordinates depend on the model of equation of state; however, usually they are represented by analogy with the coordinates introduced by van Konynenburg and Scott [1] for the van der Waals model.

$Z_{1}=\left(a_{22}-a_{11}\right) /\left(a_{22}+a_{11}\right)$,

$Z_{2}=\left(a_{22}-2 a_{12}+a_{11}\right) /\left(a_{22}+a_{11}\right)$,

$Z_{3}=\left(b_{22}-b_{11}\right) /\left(b_{22}+b_{11}\right)$,

$Z_{4}=\left(b_{22}-2 b_{12}+b_{11}\right) /\left(b_{22}+b_{11}\right)$.

Global phase diagrams for all realistic models have an extremely similar structure, particularly for the case of molecules of the same size. For example, the global phase diagrams of such different models as the equation of state for the Lennard-Jones binary fluid [23] and the Redlich-Kwong one fluid model [24] are almost identical, including such sensitive phenomena as the presence of closed immiscibility regions. Accordingly, most of assumptions and conclusions based on the studied models of phase behavior can be transferred to other cases.

Figure 2 shows the global phase diagram for binary mixtures of equal-sized molecules, plotted in the twodimensional $\left(Z_{1}-Z_{2}\right)$ space. One of the most important boundaries is visualised by the tri-critical points (TCP). This boundary divides the classes I and V, II and IV, or

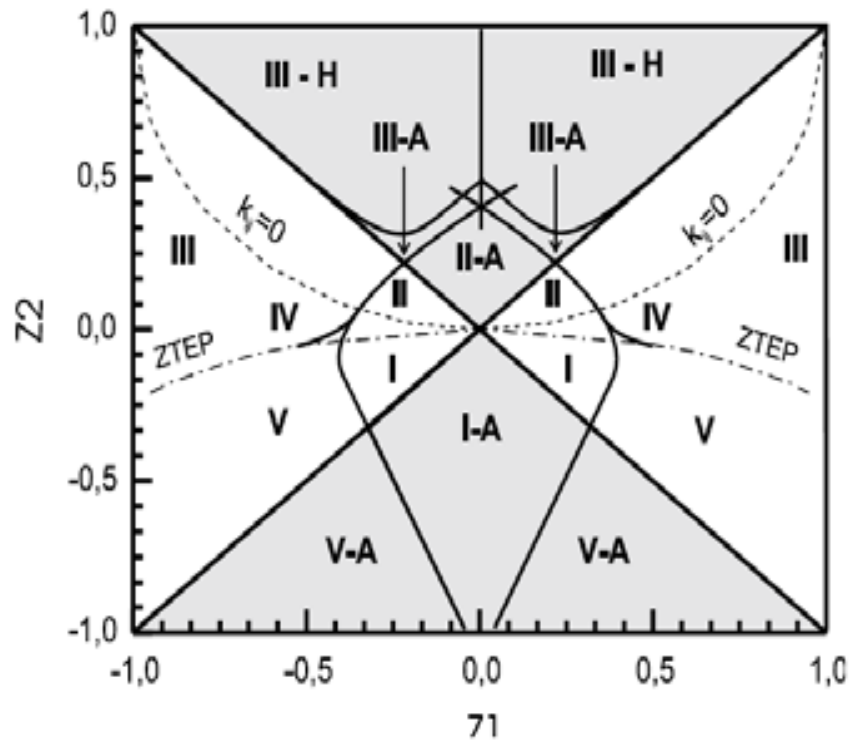

Figure 2: Global phase diagram for the Redlich - Kwong [24] one fluid model of equation of state.
III and IV. The tri-critical state is a state, where the regions of the liquid-liquid-gas immiscibility shrink to one point, which is named the TCP. Three phases become identical at a TCP. Another important boundary in the global phase diagrams is the locus of double critical end-points (DCEP) that divides types III and IV, or II and IV.

Type IV is characterised by two liquid-liquid-gas curves. One is at high temperatures and is restricted by two critical end points [one lower critical end point (LCEP) and an upper critical end point (UCEP)]. At the upper critical end point, the solution (compounds) become(s) immiscible as the temperature is lowered. At a lower critical end point, the solution separates into two phases as the temperature is increased. A DCEP occurs in a type IV when LCEP high-temperature threephase region joins the UCEP of low-temperature threephase region. A DCEP is produced in a type III system when the critical curve cuts tangentially the threephase line in a pressure - temperature diagram.

Type $\mathrm{V}$ resembles type IV which has no liquid-liquid critical line and three phase line at low temperatures. For this type, the occurrence of azeotropic states and multiextremal critical lines is possible (type V-A). The types I and II, or IV and V, differ in the existence of a three-phase line, which goes from high pressures to an UCEP. For this case, the boundary situation is defined by the zero-temperature end point (ZTEP). Thermodynamic expressions and mathematical tools are given in the literature [25].

The equation of state parameters for components of refrigerant - imidazolium-based IL mixtures under study are given in Table $\mathbf{1}$.

\section{PHASE EQUILIBRIA IN REFRIGERANT - IONIC LIQUID BLENDS}

To estimate the possibility of refrigerant blend separation via extraction processes with IL information about phase behavior of mixtures is needed. Azeotropy breaking in binary mixtures at the IL doping indicates opportunity to apply the conventional distillation methods for component separation

One may obtain the relationships for azeotropy boundaries from the global phase diagram [shaded $\mathbf{A}$ (Azeotropy) and $\mathbf{H}$ (Hetero-azeotropy)] regions in Figure 2]. The above azeotropic boundaries are straight lines in the $\left(\mathbf{Z}_{1}, \mathbf{Z}_{2}\right)$-plane that cross at a single point in the vicinity of the centre for equal sized molecules. It opens the opportunity for obtaining the 
Table 1: The SRK Equation of State Parameters

\begin{tabular}{|c|c|c|c|c|c|c|}
\hline Components & $\begin{array}{c}\text { R744, } \\
\text { REFPROP } \\
\text { [26] }\end{array}$ & $\begin{array}{l}\text { R134a, } \\
\text { REFPROP } \\
\text { [26] }\end{array}$ & $\begin{array}{c}\text { R1234yf, } \\
\text { Tanaka, } \\
\text { Higashi, [27] }\end{array}$ & $\begin{array}{l}{[E M I m]\left[\mathrm{Tf}_{2} \mathrm{~N}\right] \text {, }} \\
\text { Ren et al., [3] }\end{array}$ & $\begin{array}{l}\text { [HMIm] }\left[\mathrm{BF}_{4}\right] \text { Ren, } \\
\text { Scurto, [29] }\end{array}$ & $\begin{array}{c}{\left[\mathrm{C}_{10} \operatorname{mim}\right]\left[\mathrm{Tf}_{2} \mathrm{~N}\right],} \\
\text { Bogel-Łukasik et } \\
\text { al., [28] }\end{array}$ \\
\hline Tc, $\mathrm{K}$ & 304.13 & 374.3 & 367.85 & 808.82 & 679.1 & 1345.1 \\
\hline $\mathrm{Pc}, \mathrm{MPa}$ & 7.3773 & 4.06 & 3.38 & 2.03 & 1.79 & 1.87 \\
\hline$\omega$ & 0.22394 & 0.3268 & 0.28 & 0.3 & 0.926 & 0.5741 \\
\hline
\end{tabular}

series of inequalities to separate azeotropic and zeotropic regions of the global phase diagram. Selection criterion for azeotrope for the SRK one fluid equation of state for binary mixture in global phase diagram variables was derived by Artemenko and Mazur [30]:

$Z_{2}=\mp Z_{1}-0.67\left(1 \pm Z_{1}\right)\left(\frac{1-Z_{4}}{1 \pm Z_{3}}-1\right)$,

where the upper signs «+» or «-» correspond to the value of the composition of critical azeotropic point at $x_{C}$ $=0$, the lower at $x_{c}=1$. According to equation (8), in the $Z_{1}-Z_{2}$ plane, at fixed values $Z_{3}$ and $Z_{4}$, the boundary that separates the zeotropic and azeotropic states is a straight line). If a characteristic point is located in the northern or southern quadrants (Figures $2,3)$ then azeotropy phenomena should appear in the binary refrigerant mixture.

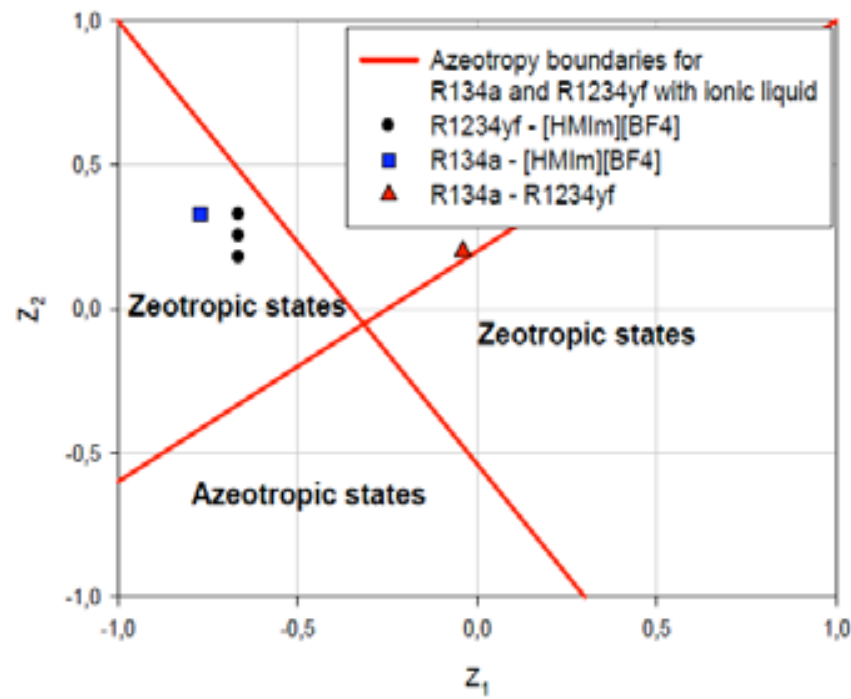

Figure 3: Allocation of characteristics points on global phase diagram for refrigerant blend R134a and R1234yf with ionic liquids.

Qualitative pattern of characteristic point allocation for the IL $[\mathrm{HMIm}]\left[\mathrm{BF}_{4}\right]$ + refrigerants R134a (R1234yf) systems is illustrated in Figure 3. Refrigerant R1234yf was chosen as expected low GWP alternative for
R134a. No experimental data for this system are available in literature. The azeotropy boundaries are

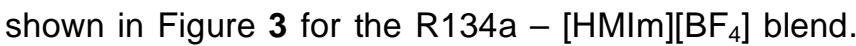
The boundaries for the R1234yf - $\left.[\mathrm{HMIm}] \mathrm{BF}_{4}\right]$ blend practically coincide. Azeotropy is clearly appeared in the R134a - R1234yf system (Figure 3). The IL doping to azeotropic mixture leads to an azeotropy breaking that demonstrate the phase envelope for the R134a R1234yf - $[\mathrm{HMIm}]\left[\mathrm{BF}_{4}\right]$ blend in Figure 4. The phase equilibria calculations were realized in MATLAB software on the base of the Michelsen - Mollerup algorithms [31].

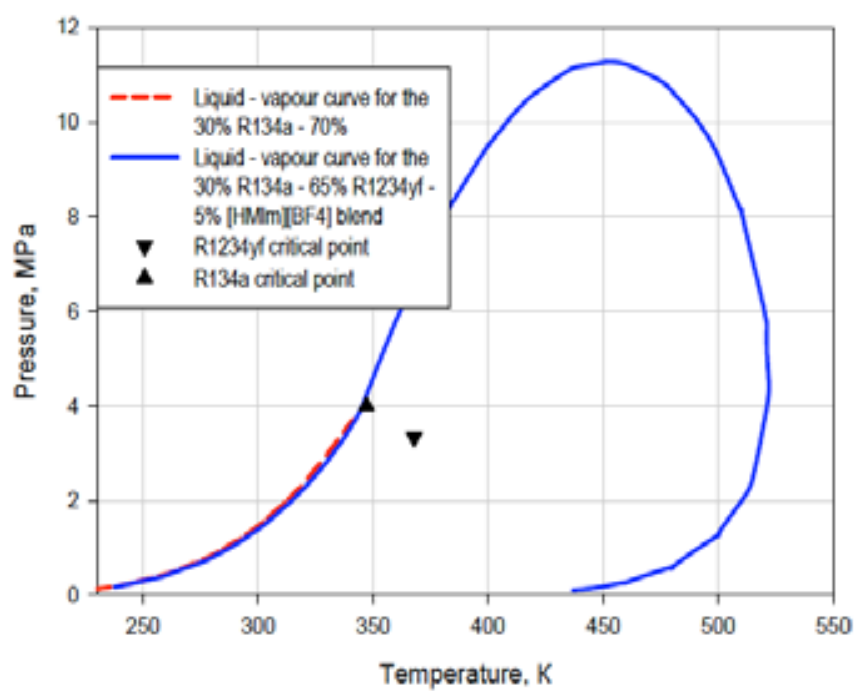

Figure 4: Azeotropy breaking in the R134a - R1234yf blend at ionic liquid doping.

\section{RESULTS AND DISCUSSION}

The most interesting system for refrigeration application is a system refrigerant $\mathrm{R} 134 \mathrm{a}+$ imidazolium-based ILs [3, 29]. The anion group tuning alters the intermolecular interaction between refrigerant and IL that change phase behavior of this system in whole.

\subsection{R134a - Imidazolium-Based Ionic Liquid Blend}

Fluid phase equilibria modeling contains very important information to design the generator of 
absorption refrigerating machines. The phase equilibria calculations for imidazolium-based ionic liquids with refrigerants $\mathrm{R} 134 \mathrm{a}$ and $\mathrm{R} 1234 \mathrm{yf}$ is carried out via the Soave - Redlich - Kwong one fluid model equation of state using parameters regressed at the low pressure experimental data. The phase behavior of imidazoliumbased ionic liquids: $\mathrm{C}_{8} \mathrm{H}_{11} \mathrm{~N}_{3} \mathrm{~F}_{6} \mathrm{~S}_{2} \mathrm{O}_{4}$ ([EMIm] [Tf2N]) and $\mathrm{C}_{10} \mathrm{H}_{19} \mathrm{~N}_{2} \mathrm{BF}_{4}\left([\mathrm{HMIm}]\left[\mathrm{BF}_{4}\right]\right)$ with concurrent refrigerants $\mathrm{R} 134 \mathrm{a}$ and R1234yf is evaluated (Figures 5-7).

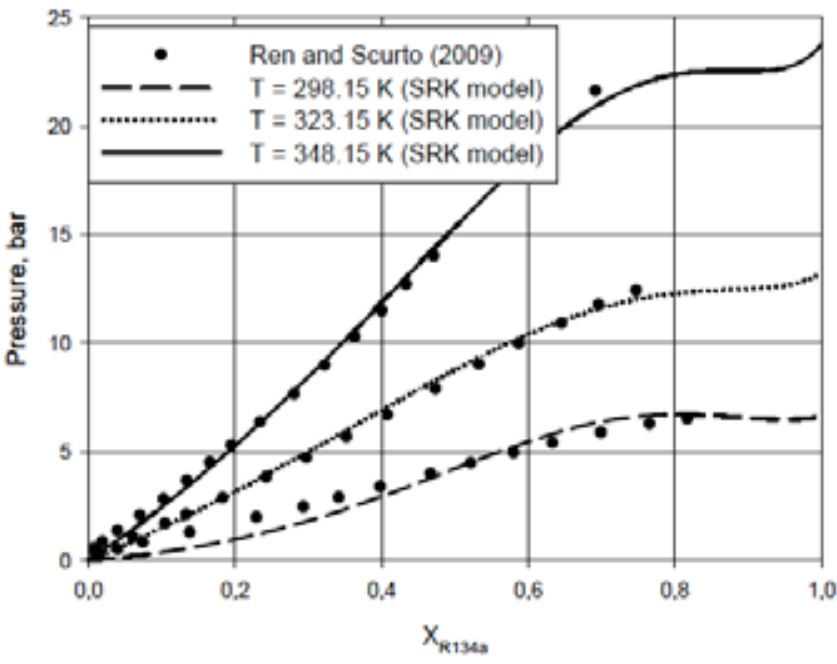

Figure 5: $\mathrm{P}-\mathrm{x}, \mathrm{y}$ diagram for binary mixture $\mathrm{R} 134 \mathrm{a}-$ [EMIm][Tf2N] $\left(k_{12}=0.1216(0.0799)(0.0857)\right.$ and $I_{12}=0.0874$ (0.0266) (0.0250) for temperatures $298.15 \mathrm{~K}, 323.15 \mathrm{~K}$. and $348.15 \mathrm{~K}$, correspondingly).

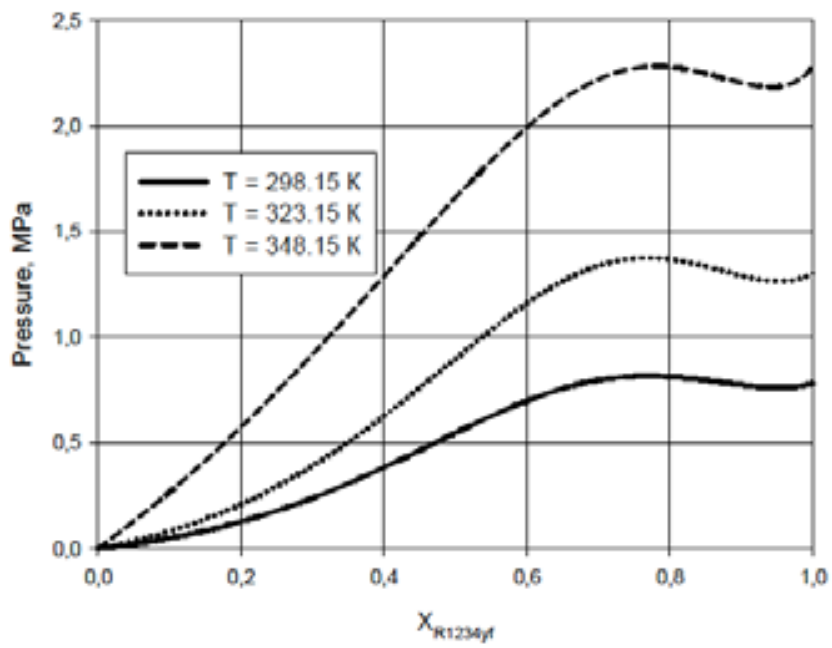

Figure 6: $\mathrm{P}-\mathrm{x}, \mathrm{y}$ diagram for binary mixture R1234yf [EMIm] [Tf2N] $\left(k_{12}=0.1216(0.0799)(0.0857)\right.$ and $l_{12}=0.0874$ (0.0266) (0.0250) for temperatures $298.15 \mathrm{~K}, 323.15 \mathrm{~K}$. and $348.15 \mathrm{~K}$, correspondingly).

The anionic group variation leads to critical point shift of ILs and changes the intermolecular interactions between IL and refrigerant molecules. As result the types of phase behaviour are also changed. Variation of the interaction coefficient $k_{12}$ shifts the position of

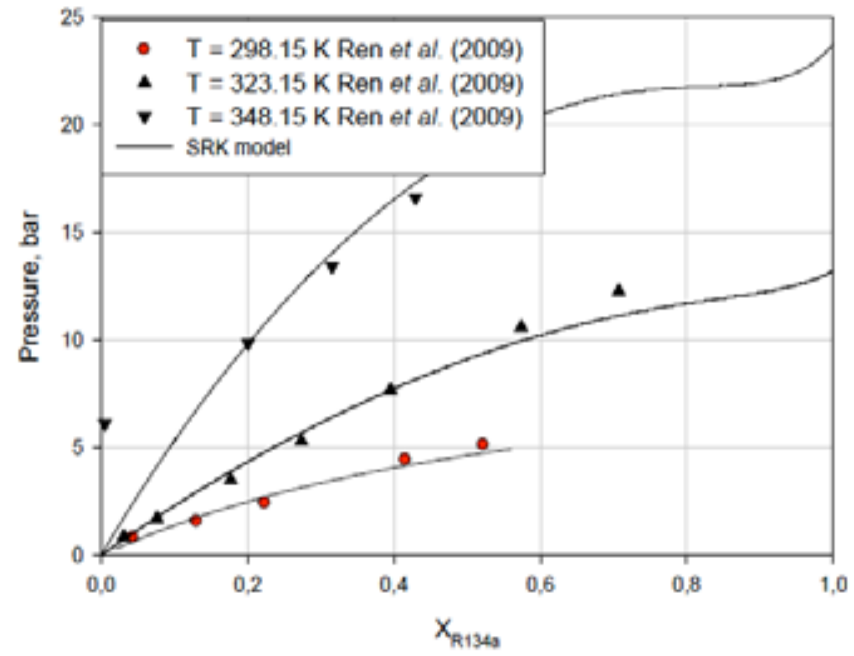

Figure 7: $\mathrm{P}-\mathrm{x}, \mathrm{y}$ diagram of the binary R134a $[\mathrm{HMIm}]\left[\mathrm{BF}_{4}\right]$ system $\left(k_{12}=0.1526(0.0815)(0.0300) ; l_{12}=\right.$ $0.0801(-0.025)(-0.080)$ for temperatures $298.15 \mathrm{~K}$, $323.15 \mathrm{~K}$, and $348.15 \mathrm{~K}$, correspondingly).

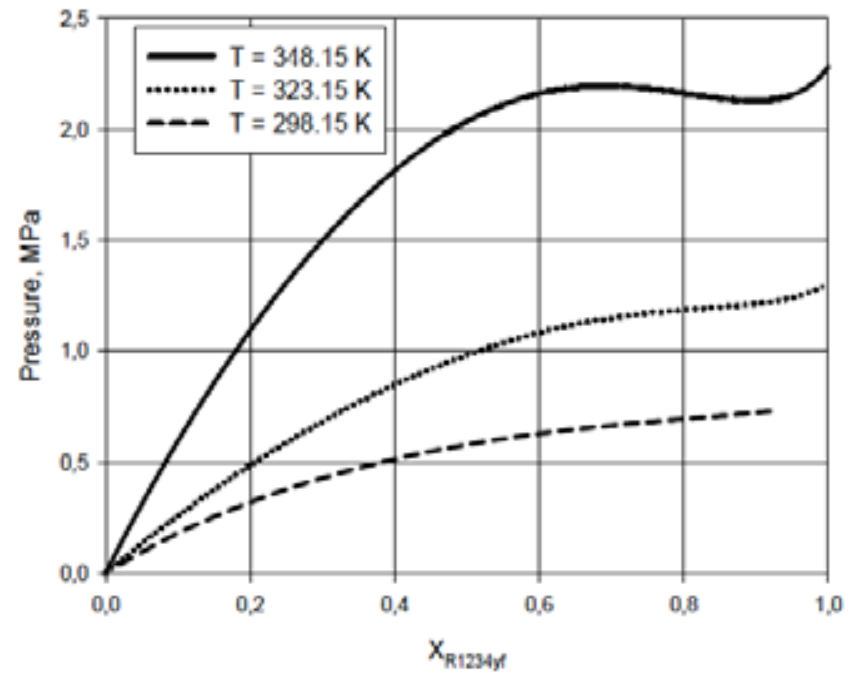

Figure 8: $P-x, y$ diagram of the binary R1234yf $[\mathrm{HMlm}]\left[\mathrm{BF}_{4}\right]$ system $\left(k_{12}=0.1526(0.0815)(0.0300) ; l_{12}=\right.$ $0.0801(-0.025)(-0.080)$ for temperatures $298.15 \mathrm{~K}$, $323.15 \mathrm{~K}$, and $348.15 \mathrm{~K}$, correspondingly).

characteristic point on global phase diagram. For

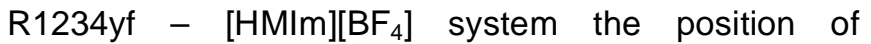
characteristic point at different values $k_{12}=-0.1,0,+$ 0.1 is illustrated in Figure 3 and demonstrates a tendency to transition from azeotropic to zeotropic state or vice versa. The binary interaction parameters $k_{12}$ and $I_{12}$ for R134a - II blends were restored from experimental data Ren et al. [3] and Ren, Scurto [29]. Analysis of the isotherm behavior shows that temperature decreasing can produce the isotherm "perestroyka" with appearance upper critical end point (UCEP) and new three phase line. Uncertainty in determination of binary interaction parameters requires additional experimental data to make decision 
concerning most likely type of phase behavior (III, IV or $\mathrm{V}$ type). From positive value of binary interaction coefficient $k_{12}$ it is most likely to suggest III-type of phase behavior for system under study.

\subsection{Azeotropy in R744 - Ionic Liquid Blends}

Among huge amount of different attempts to use of ILs as media for $\mathrm{CO}_{2}$ /gas separation the systems $\mathrm{R} 744$ - ILs look promising, since $\mathrm{CO}_{2}$ is more highly soluble in comparison with other gases. The R744 - ILs blends are also next-generation working fluid for vapor compression refrigerating machines. Ionic liquid based refrigerants provide more efficient ways of using carbon dioxide as a refrigerant in absorption and vapor compression cooling systems. The R744 cooling systems require very high pressure to operate and the IL doping gives an opportunity to reduce a discharge pressure.

Ratio of critical temperatures R744 and ILs defines the range of existence for given type of phase behavior.

A large difference between critical temperatures $\mathrm{R} 744$ and IL defines a limit value $Z_{1} \rightarrow 1$ in the global phase diagram. It allows considering only III and $\mathrm{V}$ types (Figure 2) as a possible scenario of phase behavior. Type IV occupies a very small region in global phase diagram. For large critical temperatures of ILs and the binary interaction coefficients $k_{12}>-0.2$ it is more likely to appear type III of phase behavior in the R744 - IL system. A possible azeotropic states can appear as a type III-A if hypothetic IL critical temperature will not exceed $600 \mathrm{~K}$. The evolution of

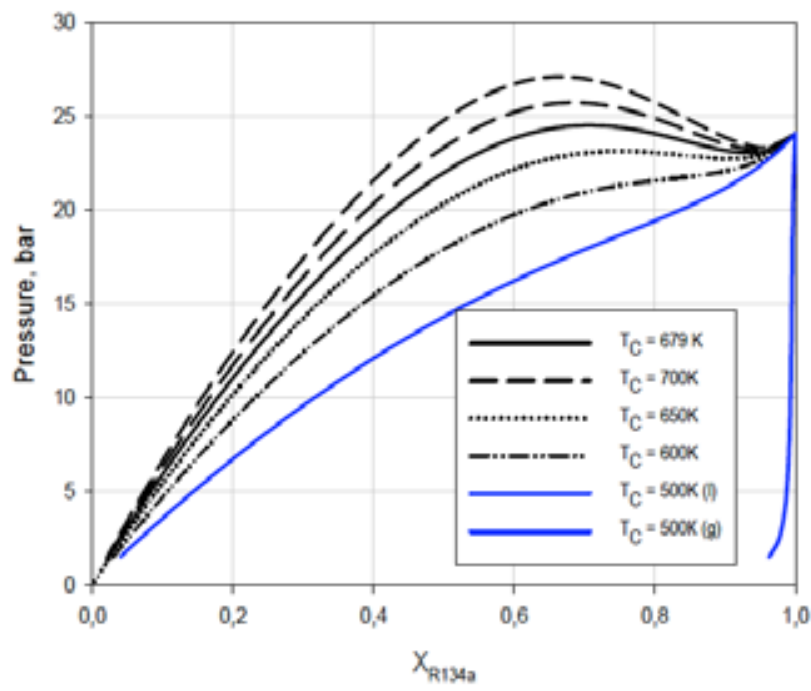

Figure 9: Influence of the IL critical point shift on phase equilibria in the refrigerant + IL blends $(T=323.15 \mathrm{~K})$. phase behavior at IL critical point shift is illustrated in Figure 9. Modeling of type $\mathrm{V}$ constrains the binary interaction coefficient that should be negative. To decrease vapour pressure R744 and to form a negative azeotrope in the R744 - IL system a large negative value of $k_{12}$ is needed. For existing refrigerant - IL systems this type of phase behavior did not observed. To realize type V - A (Figure 10) the strong intermolecular interactions should appear similar for the $\mathrm{H}_{2} \mathrm{O}-\mathrm{HCl}$ system where this type is observed.

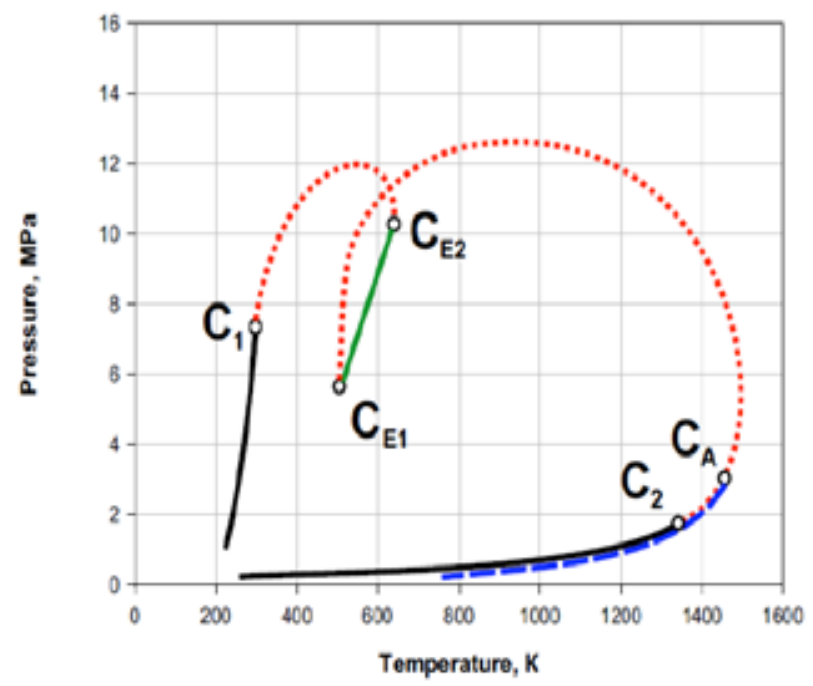

Figure 10: Eligible scenario of phase behavior in R744 + IL system to decrease saturation pressure $\mathrm{CO}_{2}$ (Type V-A). $\mathrm{C}_{\mathrm{E} 1}$ and $\mathrm{C}_{\mathrm{E} 2}$ are LCEP and UCEP, correspondingly.

\section{CONCLUSIONS}

Analysis of global phase diagram for model systems shows the binary blends of industrial refrigerants with imidazolium based ionic liquids don't exhibit azeotropy for all systems of interest in refrigeration applications. The IL doping leads to azeotropy breaking in binary refrigerant mixtures and offers an opportunity for azeotropic refrigerant mixture separation technologies to remove the environmentally harmful substances. The desirable properties of IL doping to change vaporpressure curve of $\mathrm{CO}_{2}$ for vapor compression cycle applications require the search new components providing V-A type of phase behaviour. A guided search of the functional groups that define the pseudocritical point shift in ILs is an effective tool of thermophysical property and phase behavior tuning to meet compromise among multitude of desirable physicochemical properties.

\section{REFERENCES}

[1] Van Konynenburg $P$, Scott R. Critical lines and phase equilibria in binary van der Waals mixtures. Philos Trans $R$ Soc London Ser A 1980; 298: 495-40. 
[2] Aki S, Mellein B, Saurer E, Brennecke J. High-pressure phase behavior of carbon dioxide with imidazolium-based ionic liquids. J Phys Chem B 2004; 108: 20355-65. http://dx.doi.org/10.1021/jp046895+

[3] Ren W, Scurto AM, Shiflett MB, Yokozeki A. Phase Behavior and Equilibria of Ionic Liquids and Refrigerants: 1-Ethyl-3methyl-imidazolium Bis(trifluoromethyl-sulfonyl) imide [EMIm] [Tf2N]) and R-134a In Gas-Expanded Liquids and NearCritical Media; Hutchenson, K., el al.; ACS Symposium Series; American Chemical Society: Washington, DC. 2009; pp. 112-128.

[4] Shiflett M, Yokozeki A. Binary Vapor-Liquid and VaporLiquid-Liquid Equilibria of Hydrofluorocarbons (HFC-125 and HFC-143a) and Hydrofluoroethers (HFE-125 and HFE- 143a) with Ionic Liquid [emim][Tf2N]. J Chem Eng Data 2008; 5: 492-97. http://dx.doi.org/10.1021/je700588d

[5] Shiflett M, Yokozeki A. Liquid-liquid equilibria in binary mixtures of 1,3-propanediol + ionic Liquids [bmim][PF6], [bmim] [BF4], and [emim][BF4]. J Chem Eng Data 2007; 52: 1302. http://dx.doi.org/10.1021/je700037z

[6] Shiflett M, Yokozeki A. Liquid-Liquid Equilibria of Hydrofluoroethers and Ionic Liquid Ethyl-3-methylimidazolium Bis (trifluoro-methyl sulfonyl)imide. J Chem Eng Data 2007; 52: 2413-18.

http://dx.doi.org/10.1021/je700365z

[7] Shiflett M, Yokozeki A. High-pressure phase equilibria of \{carbon dioxide (CO2) + n-alkyl- imidazolium bis(trifluoromethylsulfonyl)amide\} ionic liquids. J Phys Chem B 2007; 111: 2070-74. http://dx.doi.org/10.1021/jp067627+

[8] Shiflett M, Yokozeki A. Global Phase Behavior of Imidazolium Ionic Liquids and Compressed 1,1,1,2-Tetrafluoroethane (R-134a). Chimica Oggi/Chem Today 2006; 24: 28-30.

[9] Shiflett M, Yokozeki A. Solubility and diffusivity of hydrofluorocarbons in room- temperature ionic liquids. AIChE J 2006; 52: 1205-19.

http://dx.doi.org/10.1002/aic.10685

[10] Shiflett M, Yokozeki A. Vapor-liquid-liquid equilibria of pentafluoroethane and ionic liquid [bmim][PF6] mixtures studied with the volumetric method. J Phys Chem B 2006; 110: $14436-43$.

http://dx.doi.org/10.1021/jp062437k

[11] Shiflett M, Yokozeki A. Vapor-liquid-liquid equilibria of hydrofluorocarbons + 1-butyl-3 - methylimidazolium hexafluoro-phosphate. J Chem Eng Data 2006; 51: 1931-39. http://dx.doi.org/10.1021/je060275f

[12] Shiflett M, Yokozeki A. Global phase behaviors of trifluoromethane in ionic liquid [bmim][PF6]. Ind Eng Chem Res 2005; 44: 4453-64. http://dx.doi.org/10.1021/ie058003d

[13] Shiflett M, Harmer M, Junk C, Yokozeki A. Solubility and diffusivity of difluoromethane in room-temperature ionic liquids. J Chem Eng Data 2006; 51: 483-95.

http://dx.doi.org/10.1021/je050386z

[14] Shiflett M, Harmer M, Junk C, Yokozeki A. Solubility and diffusivity of $1,1,1,2$ - tetrafluoroethane in room-temperature ionic liquids. Fluid Phase Equil 2006; 242: 220-32. http://dx.doi.org/10.1016/j.fluid.2006.01.026

[15] Shiflett M, Kasprzak D, Junk C, Yokozeki A. Phase behavior of $\{$ carbon dioxide $+[$ bmim $][A c]\}$ mixtures. J Chem Thermodyn 2008; 40(1): 25-31.

http://dx.doi.org/10.1016/j.jct.2007.06.003
[16] Yokozeki A, Shiflett M. Vapor-liquid equilibria of ammonia + ionic liquid mixtures. Appl Energy 2007; 84: 1258-73. http://dx.doi.org/10.1016/j.apenergy.2007.02.005

[17] Raeissi S, Florusseb L, Peters C. Scott-van Konynenburg phase diagram of carbon dioxide + alkylimidazolium-based ionic liquids. J Supercritical Fluids 2010; 55: 825-32. http://dx.doi.org/10.1016/j.supflu.2010.09.042

[18] Redlich O, Kwong JN. On the Thermodynamics of Solutions: V. An Equation of State: Fugacities of Gaseous Solutions. Chem Rev 1949; 44: 233-44.

[19] Soave G. Equilibrium Constants From a Modified RedlichKwong Equation of State. Chem Eng Sci 1972; 27: 1197203.

[20] Varchenko A. Evolution of convex hulls and phase transitions in thermodynamics. J Sov Math 1990; 52: 3305-25. http://dx.doi.org/10.1007/BF01095252

[21] Aicardi F, Valentin P, Ferrand E. On the classification of generic phenomena in thermodynamic binary mixtures models depending on parameters. Phys Chem Chem Phys 2002; 4: 884-95.

http://dx.doi.org/10.1039/b109105k

[22] Calm J, Hourahan G. Refrigerant Data Summary. Eng Syst 2001; 18(11): 74-88.

[23] Mazur V, Boshkov L, Murakhovsky V. Global phase behavior in binary Lennard-Jones mixtures. Phys Lett 1984; 104A: 415-18.

http://dx.doi.org/10.1016/0375-9601(84)90746-1

[24] Deiters UK, Pegg IL. Systematic Investigation of the Phase Behaviour in Binary Fluid Mixtures. I. Calculations Based on the Redlich-Kwong Equation of State. J Chem Phys 1989; 90: 6632-41. http://dx.doi.org/10.1063/1.456280

[25] Cismondi M, Michelsen M. Global Phase Equilibrium Calculations: Critical Lines, Critical End Points and LiquidLiquid-Vapour Equilibrium in Binary Mixtures. J Supercritical Fluids 2007; 39: 287-95. http://dx.doi.org/10.1016/j.supflu.2006.03.011

[26] Lemmon E, et al. NIST Reference Fluid Thermodynamic and Transport Properties- REFPROP. Version 8.0, Gaithersburg, Maryland 2007.

[27] Tanaka K, Higashi Y. Thermodynamic properties of HFO1234yf (2,3,3,3- tetrafluoropropene), In: 3rd IIR Conference on Thermophysical Properties and Transfer Processes of Refrigerants, Boulder, CO, USA 2009.

[28] Bogel-Łukasik R, Matkowska D, Bogel-Łukasika E, Hofman $\mathrm{T}$. Isothermal vapour-liquid equilibria in the binary and ternary systems consisting of an ionic liquid, 1-propanol and CO2. Fluid Phase Equilibria 2010; 293: 168-74. http://dx.doi.org/10.1016/j.fluid.2010.03.008

[29] Ren W, Scurto A. Phase equilibria of imidazolium ionic liquids and the refrigerant gas, 1,1,1,2- tetrafluoroethane (R134a). Fluid Phase Equil 2009; 286: 1-7.

http://dx.doi.org/10.1016/j.fluid.2009.07.007

[30] Artemenko S, Mazur V. Azeotropy in the natural and synthetic refrigerant mixtures. Int J Refrig 2007; 30(5): 83139.

http://dx.doi.org/10.1016/j.ijrefrig.2006.11.010

[31] Michelsen L, Mollerup J. Thermodynamic Models, Fundamentals and Computational Aspects. - Lyngby (Denmark): Department of Chemical Engineering. Technical University of Denmark 2002. 